\title{
Prospects for applications of genetic engineering in pig breeding
}

\author{
P. MULSANT, M. DALENS, Geneviève ECHARD, J. GELLIN, \\ Martine YERLE, M. GILLOIS \\ I.N.R.A., Laboratoire de Génétique Cellulaire, B.P. 27, 31326 Castanet-Tolosan Cedex
}

Genetic engineering provides an extremely high number of cloned mammalian DNA sequences. These sequences should be powerful tools for genetic analysis or improvement of the pig.

First, they can be used as gene-specific probes to identify homologous sequences in cellular DNA or chromosomes by molecular hybridization and to detect restriction fragment length polymorphisms in these homologous sequences. Thus, it can be expected that numerous polymorphic genetic markers will soon be localized at random sites on pig chromosomes. These markers will in turn be used to assign potentially important genes to precise chromosomal regions and predict genotypes at the corresponding loci. Eventually, this could lead to the isolation and cloning of some of these genes.

Next, functional genes can be introduced into cultured mammalian cells or into fertilized eggs, providing the opportunity to investigate their importance in pig's main physiological traits and possibly to produce improved transgenic pigs.

\section{V. - PATHOLOGY}

\section{Inventory and estimation of health problems : performance situation Permanent epidemiological survey of 29 breeding-finishing herds in Brittany (1978-1985)}

\author{
J.P. TILLON, F. MADEC
}

Ministère de l'Agriculture, Station de Pathologie Porcine, B.P. 9, Les Croix, 22440 Ploufragan (France)

A continuous survey of ecopathology was conducted in 29 breeding-finishing pig herds in Brittany from 1978 to 1985 . This sample chosen randomly appeared a posteriori rather representative of the most dynamic herds in France and Brittany. The various pathological manifestations and their intensity are described. Respiratory diseases (pneumonia, rhinitis) remain the main problem during the fattening period. Breeding performance was rather satisfactory. By contrast, growth performance and feed conversion ratio were not sufficient especially during the first years of the survey. They were much better later, which suggests that housing and environmental conditions have been improved. Further studies will be made to explain the variations observed and to relate them with certain elements of the management system. 